\title{
Pallidal Deep Brain Stimulation in Cervical Dystonia: Clinical Outcome in Four Cases
}

\author{
H.A. Eltahawy, J. Saint-Cyr, Y.Y. Poon, E. Moro, A.E. Lang, A.M. Lozano
}

\begin{abstract}
Objective: Report on the clinical results following bilateral globus pallidus interna deep brain stimulation in four patients (one female and three males) with severe cervical dystonia, mean age 48 years (range 37-67). Methods: All four patients had failed extensive medical and botulinum toxin treatment. The mean duration of the disease was nine years (range 4-15 years). Patients were assessed pre and postoperatively using the Toronto Western Spasmodic Torticollis Rating Scale (TWSTRS). Preoperatively, the mean TWSTRS total score was 43.2 (range 28-60.5). Posteroventral pallidal deep brain stimulators were inserted using MRI and microelectrode recording guidance. Last follow-up was 15 months for the four patients. Results: Mean reduction in the TWSTRS total scores at last follow- up was $73 \%$ (range 61- 85\%). Improvement in pain occurred soon after deep brain stimulation surgery. Motor improvement was delayed and prolonged over several months. Frequent adjustment in the stimulation parameters was necessary in the first three months. Conclusion: Bilateral pallidal stimulation is effective in management of selected cases of intractable cervical dystonia.
\end{abstract}

RÉSUMÉ: Stimulation cérébrale profonde du globus pallidus dans la dystonie cervicale: résultats cliniques chez quatre patients. Objectif: Nous rapportons les résultats cliniques de la stimulation bilatérale de la pars interna du globus pallidus chez quatre patients, une femme et trois hommes dont l'âge moyen était de 48 ans (écart de 37 à 67 ans), présentant une dystonie cervicale sévère. Méthodes: Les traitements médicamenteux et l'injection de toxine botulique s'étaient avérés un échec chez ces quatre patients. La durée moyenne de la maladie était de neuf ans (écart de 4 à 15 ans). Les patients ont été évalués au moyen du Toronto Western Spasmodic Torticollis Rating Scale (TWSTRS) avant et après l'opération. Avant l'opération, le score total moyen était de 43,2 (écart de 28 à 60,5). Des stimulateurs ont été implantés dans la région postéroventrale du globus pallidus sous guidage par IRM et enregistrement par microélectrodes. Le suivi a été de 15 mois pour chaque patient. Résultats: La diminution moyenne des scores totaux au TWSTRS au moment du dernier examen de suivi était de $73 \%$ (écart de $61 \%$ à 85 $\%$ ). La douleur s'est améliorée tôt après la chirurgie. Cependant, l'amélioration motrice a été plus tardive et s'est maintenue pendant plusieurs mois. Il a fallu procéder à des ajustements fréquents du réglage des conditions de stimulation pendant les trois premiers mois. Conclusion: La stimulation pallidale bilatérale est efficace dans le traitement de certains cas de dystonie cervicale réfractaire au traitement.

Can. J. Neurol. Sci. 2004; 31: 328-332

Spasmodic torticollis is the commonest form of adult-onset focal dystonia. ${ }^{1,2}$ The overall incidence has been estimated at $1.2 / 100,000$ person-year with a female:male ratio of approximately $4: 1 .^{3}$ It can cause significant functional impairment with interference with daily activities and sometimes work. The standard treatment for most patients with cervical dystonia (CD) is repeated botulinum injections. ${ }^{4,5}$ However, in a selected group of patients, primary or secondary failure of botulinum injections occurs due to a change in muscles involved in dystonia or more frequently the development of immunoresistance in $3-10 \%$ of cases. ${ }^{4}$ In these cases, surgical treatment can be considered. The multitude of surgical techniques reported in the literature indicates that the optimum operation for cervical dystonia is yet to be devised. Peripheral procedures (reviewed by Villavicencio ${ }^{6}$ ) have involved resection of cervical muscles, selective peripheral denervation, intradural rhizotomy,

From the Toronto Western Hospital, Division of Neurosurgery, (HAE, JS-C, AML); Neurology Department, (YYP, EM, AEL); Toronto, Ontario, Canada; Ain Shams University Hospitals, Neurosurgery Department, Cairo, Egypt (HAE). Received July 22, 2003. ACCePted infinalform DeCEMBer 16, 2003. Reprint requests to: Andres M Lozano, 399 Bathurst Street, Division of Neurosurgery, 4th floor, West Wing, Toronto, Ontario, M5T2S8 Canada. 
iontophoresis of the vestibular apparatus in inner ear, and microvascular decompression of the accessory nerve. Most of the previous surgical procedures can, unfortunately, lose benefit over time. ${ }^{7}$ Simultaneously, interest has grown in the possibility that disorders of the thalamus and basal ganglia may underlie cervical dystonia. As early as 1954, Hassler and Hess ${ }^{8}$ targeted the ventralis oralis internus of the thalamus for cervical dystonia. Many series followed ${ }^{9-12}$ reporting only modest results with high complication rates associated with bilateral thalamotomy. More recently, some attention has turned to the role of the globus pallidus in the pathogenesis of dystonia. Positron emission tomography studies ${ }^{13}$ and microelectrode recording in patients with generalized dystonia have demonstrated ${ }^{14,15}$ what appears to be dysfunctional neuronal activity in the globus pallidus interna (GPi). Many reports over the past decade have confirmed the effectiveness of pallidal lesions or deep brain stimulation (DBS) in relieving levo-dopa induced dyskinesia and dystonia in parkinsonian patients. This encouraged the application of pallidal procedures for generalized dystonia with promising results. $^{14,16-19}$ In the past few years, several reports have described the use of pallidal DBS in patients with generalized dystonia. In this retrospective study, we report the clinical response of four patients with cervical dystonia treated with GPi DBS. A short report on three of these patients with six months postsurgery follow-up has appeared in the context of an article comparing the surgical outcome in primary versus secondary dystonia. $^{20}$

\section{METHODS}

Between January 2000 and February 2002 four patients with cervical dystonia refractory to medical treatment and botulinum toxin injections underwent GPi DBS surgery. In addition to being refractory to treatment, patients were selected for surgery based on the degree of functional disability caused by the dystonia. Each patient was formally assessed by a movement disorder neurologist (AEL). The assessment included video taping and pre-operative scoring using the Toronto Western Spasmodic Torticollis Scale (TWSTRS). ${ }^{21-23}$ Using standard stereotactic and microelectrode recording techniques similar to those previously described for pallidal targeting for Parkinson's disease,${ }^{24}$ bilateral simultaneous insertion of quadripolar DBS electrodes into the sensorimotor region in the posteroventral GPi was performed. Postoperative MRI confirmed the location of the electrodes in the GPi. Deep brain stimulation started four weeks after the operation to allow recovery from the insertional effects of surgery. Fine tuning of the programming was performed when necessary to optimize clinical response. Postoperative TWSTRS was performed by a nonstudy neurologist from videos. Patients were assessed at two, six and 15 months after surgery.

\section{SUMMARY OF CASES}

\section{Patient 1}

This is a 50 -year-old male computer programmer. Ten years ago, after a minor head injury, he first noticed head tremor and neck pain. This progressed to persistent head rotation to the left, associated with bouts of more severe spasms every few months with inability to turn the head to the right. He noted that his torticollis was worse in the morning and had experienced modest relief with alcohol intake. Family history was non-contributory. There was little benefit from pharmacotherapy, which included trihexyphenidyl and clonazepam and, similarly, the initial good response to botulinum injections subsequently waned. He received 12 sets of injections of botulinum toxin before the ongoing therapeutic benefit was lost due to development of immunity. Examination showed a no-no head tremor with tonic contraction of the neck muscles causing the head to be pushed forwards, the chin elevated and his head turned to the left. An EMG showed 5-6 Hz tremor bursts lasting 50-100 msec and occuring synchronously in both sternomastoids and the left trapezius and alternating with a similar frequency in the right trapezius and splenius capitis. Brain MRI was normal. His pre-operative TWSTRS score was 39. On January 2000, he underwent bilateral GPi DBS electrodes insertion. At six weeks follow-up, two weeks after the stimulator was turned on, the first response noticed by the patient was marked easing of the neck pain. This was followed by gradual improvement in his level of disability even before improvement in the head rotation began. Steady improvement in the severity of the torticollis became noticeable afterwards which was maintained in subsequent follow-up visits. At 15 months follow-up his TWSTRS score was 6 . His scores at serial follow-up are shown in Table 1 and his stimulation parameters are provided in Table 2.

\section{Patient 2}

This 37-year-old welder had been unable to work for three years due to $\mathrm{CD}$. One year earlier, his symptoms started with pain in the right posterior aspect of the neck. He then developed torticollis with head turned to the right. The head could be turned to neutral position by touching the chin (geste antagonistique). His torticollis interfered with his ability to work and carry out everyday activities such as driving. His mother also had cervical dystonia. There was no significant history of trauma. Examination showed torticollis with head turned to the right associated with retrocollis and hypertrophy of the left sternomastoid and right splenius capitis. Previous treatment included artane, clonazepam and six courses of botulinum toxin injections. He was considered for surgery when these modalities proved therapeutically ineffective. His pre-operative TWSTRS score was 28. Stimulation started four weeks after surgery. After two weeks of continuous stimulation, there was no cervical pain and the severity of head rotation was reduced. This allowed for improvement in daily functioning that was maintained at subsequent visits. At six months, the severity of torticollis increased and this necessitated changing the parameters of stimulation with resumption of therapeutic benefit (Table 2). The frequency of stimulation was higher on the left stimulator, contralateral to the direction of his head rotation. He was able to maintain his head in the neutral position for most of the day and this allowed his return to work. His TWSTRS score at 15 months postoperatively was 11 (Table 1).

\section{Patient 3}

This 67-year-old, left-handed female had a 15-year history of head tremor and torticollis to the left associated with sustained neck pain. She could correct the torticollis by pushing with her hand on the right chin. There was progressive worsening and, recently, the torticollis was associated with deviation and twisting of the mouth towards the left and mild writer's cramp. The severe torticollis and neck pain interfered with activities of daily living such as reading, watching television and sleep. There was no significant family history or previous trauma. On examination, there was a no-no dystonic head tremor. The head was turned to the left with left shoulder elevation. Her right sternomastoid, left trapezius and splenius capitis were firm. Brain MRI was normal. 
Table 1: Summary of patients'demographic data, TWSTRS scores in serial follow-up and side effects

\begin{tabular}{|c|c|c|c|c|c|c|c|c|c|c|c|}
\hline $\begin{array}{l}\text { Case } \\
\text { No }\end{array}$ & Sex & $\begin{array}{c}\text { Age at } \\
\text { onset/ yrs }\end{array}$ & Duration & $\begin{array}{l}\text { Clinical } \\
\text { presentation }\end{array}$ & Associations & Pre op TV & ISTRS & $2 \mathrm{~m}$ & $6 \mathrm{~m}$ & $15 \mathrm{~m}$ & Side effects \\
\hline \multirow[t]{4}{*}{1} & M & 40 & 10 & Left Torticollis & Mild head & Severity & 14 & 11 & 5 & 4 & \multirow{16}{*}{$\begin{array}{l}\text { Flashes of light with } \\
\text { lower contacts } \\
\text { necessitating the use o } \\
\text { higher contacts }\end{array}$} \\
\hline & & & & No-No tremor & trauma & Pain & 10 & 1 & 0 & 0 & \\
\hline & & & & & & Disability & 15 & 3 & 2 & 2 & \\
\hline & & & & & & Total & 39 & 15 & 7 & 6 & \\
\hline \multirow[t]{4}{*}{2} & M & 33 & 4 & Rt torticollis & Family & Severity & 21 & 8 & 10 & 9 & \\
\hline & & & & Retrocollis & history & Pain & 0 & 0 & 0 & 0 & \\
\hline & & & & & & Disability & 7 & 8 & 2 & 2 & \\
\hline & & & & & & Total & 28 & 16 & 12 & 11 & \\
\hline \multirow[t]{4}{*}{3} & $\mathrm{~F}$ & 52 & 15 & Left torticollis & Mild facial \& & Severity & 20 & 19 & 16 & 12 & \\
\hline & & & & Shoulder elevation & hand dystonia & Pain & 7 & 0 & 0 & 0 & \\
\hline & & & & No-No tremor & & Disability & 19 & 10 & 10 & 3 & \\
\hline & & & & & & Total & 46 & 29 & 26 & 15 & \\
\hline \multirow[t]{4}{*}{4} & M & 26 & 11 & Left torticollis & Family history & Severity & 22 & 12 & 5 & 5 & \\
\hline & & & & & & Pain & 17.5 & 3 & 3 & 3 & \\
\hline & & & & & & Disability & 21 & 9 & 4 & 4 & \\
\hline & & & & & & Total & 60.5 & 24 & 12 & 12 & \\
\hline
\end{tabular}

TWSTRS = Toronto Western Spasmodic Torticollis Rating Scale

\section{Table 2. Stimulating current output parameters}

\begin{tabular}{lllrccc}
\hline Case no. & \multicolumn{2}{c}{ Amplitude (v) } & \multicolumn{2}{c}{ Pulse width (msec) } & \multicolumn{2}{c}{ Frequency $(\mathbf{H z})$} \\
& Rt. & Lt. & Rt. & Lt. & Rt. & Lt. \\
Pt 1 & 1.6 & 1.1 & 210 & 210 & 130 & 130 \\
Pt 2 & 3 & 3 & 90 & 120 & 135 & 185 \\
Pt 3 & 2.8 & 2.8 & 400 & 120 & 160 & 160 \\
Pt 4 & 2.2 & 2.6 & 210 & 60 & 130 & 130 \\
Mean & \multicolumn{2}{c}{2.4} & & 180 & \multicolumn{2}{c}{145} \\
\end{tabular}

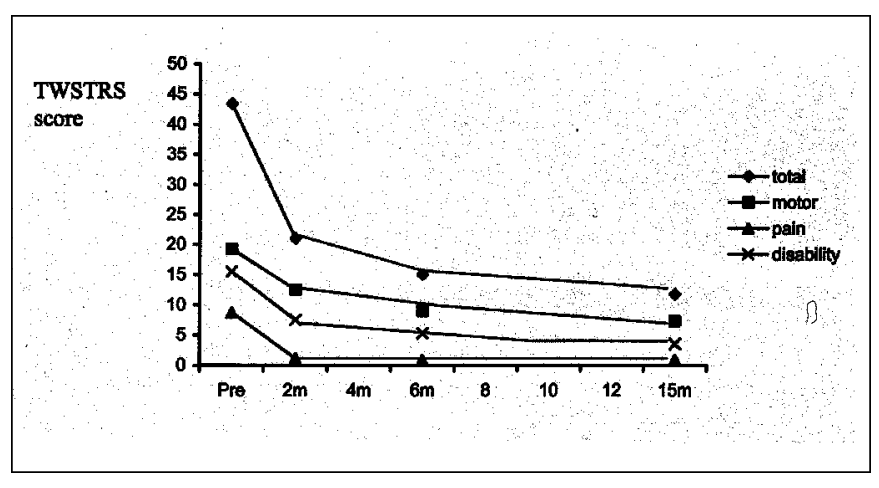

Figure: Changes in the TWSTRS mean total and sub scores over time after pallidal DBS. Data for the four patients was pooled to estimate the mean scores.

Table 3: Reports on Globus pallidus interna deep brain stimulation ${ }^{24-30}$

\begin{tabular}{llcll}
\hline Study & $\begin{array}{l}\text { Unilateral vs } \\
\text { bilateral }\end{array}$ & $\begin{array}{l}\text { No. of } \\
\text { patients }\end{array}$ & $\begin{array}{l}\text { Length of } \\
\text { follow-up }\end{array}$ & Mean improvement \\
Krauss et al, 1999 & Bilateral & 3 & $6-15 \mathrm{~m}$ & $40-80 \%$ in TWSTRS \\
Iskelel et al, 1999 & Unilateral & 1 & $3 \mathrm{w}$ & Improved \\
Kulisevsky et al, 2000 & Bilateral & 2 & $17-24 \mathrm{~m}$ & Improved pain but not severity \\
Parkin et al, 2001 & Bilateral & 3 & $2-6 \mathrm{~m}$ & Improved \\
Andaluz et al, 2001 & Bilateral & 1 & $8 \mathrm{~m}$ & $50 \%$ TWSTRS \\
Krauss et al, 2002 & Bilateral & 8 & $20 \mathrm{~m}$ (mean) & 60.7\% TWSTRS \\
Bereznai et al, 2002 & Bilateral & 2 & $10 \mathrm{~m}$ & Marked improvement but partial recurrence in one \\
& & & & patient after 3 m.
\end{tabular}


Pharmacotherapy including artane, primidone and clonazepam was of limited benefit. After an initial good response, botulinum therapy became ineffective after 11 courses. Her pre-operative TWSTRS score was 46. She received bilateral GPi DBS on May 2001. After the stimulator was turned on, there was a marked reduction in pain that was evident in the first few weeks. Various stimulation parameters were tried before settling on $160 \mathrm{~Hz}$, a frequency producing optimal motor benefit. Stimulation parameters are shown in Table 2. The last follow-up was at 15 months when her total scores were 15 (Table 1).

\section{Patient 4}

A 37-year-old man noticed head tilt to the left 11 years ago. He previously worked as a butcher but was unable to work over the past five years because of his symptoms. Initially the head tilt would last for one to two hours with no pain. By 1996, the symptoms became more frequent with continuous head drift to the left and inability to resume neutral posture associated with severe neck pain. Notably, his maternal aunt had torticollis. His medications included gabapentin, benztropin and lorazepam. He had a total of 14 sets of botulinum injections between 1998-1999 with suboptimal or no improvement.

On examination, there was marked limitation of head turning to the right. The left trapezius and the right sternomastoid were hypertrophied. His pre-operative TWSTRS scores total score was 60.5. On January 2002, he had bilateral pallidal deep brain stimulators. His neck pain improved once the stimulators were turned on. There was mild head tremor that resolved with readjustment of the output parameters. At two months follow-up, his TWSTRS total score was 24. After that there was nearly complete resolution of his torticollis and he was able to perform all daily activities independently. However, he was not able to return to work due to persistent psychosocial problems related to alcohol abuse. His total TWSTRS score at 15 months follow-up was 12 (Table 1).

\section{DISCUSSION}

In this report, we show improvement of 85, 61, 67 and $80 \%$ in the total TWSTRS scores of four patients with refractory cervical dystonia after bilateral GPi DBS insertion at 15 month follow-up. At last follow-up, the mean total score was 11, a 74\% reduction from the mean pre-operative score of 43.4. There were no serious intra- or postoperative complications.

In these patients, the earliest and most profound improvement occurs in the pain subscore with nearly total disappearance of pain by two months after the operation i.e. one month after turning the stimulators on (Figure). This is evident in the three patients (no 1, 3 and 4) who presented with baseline pain score of 10, 7 and 17.5. Patient 2 did not have pain at the pre-operative assessment and remained pain free postoperatively. The nearly immediate disappearance of pain contributes to the gain in functional status as reflected by reduction in the mean disability score by almost $50 \%$ as early as four weeks after turning the stimulators on (at two months follow-up). The improvement in the motor severity score was more gradual. At two months, there was only $35 \%$ improvement in mean severity subscore of the TWSTRS which measures the degree of motor dysfunction and dystonia. However, reduction in this score (denoting progressive improvement in the severity of torticollis) continued for more than six months follow-up in the four patients (Figure).

Previous reports ${ }^{25,26}$ have shown that pain improves before the other components of CD (two patients in Kulisevsky et $\mathrm{al}^{26}$ and one patient in Krauss et al. ${ }^{25}$ ) It is possible that the relaxation of the dystonic muscles and reduction in tremor induced by pallidal stimulation is first manifest by alleviation of musculogenic pain in the previously overactive muscles. There could, in addition, be a central effect on pain processing and perception with pallidal intervention. The delayed and progressive motor improvement may involve resolution in long standing muscle hypertrophy resolves or reversal in adaptive or neuroplasticity changes which may have occurred secondary to the long standing dystonia.

Most of the improvement was gradual with the majority of benefit occurring within the first six months (Figure) specifically in the one to two months after turning on the pulse generator. A number of groups ${ }^{25-31}$ have reported their results of pallidal DBS in a total of 12 patients with CD at varying lengths of follow-up (Table 3). Similar to our cases, the improvement in torticollis severity has been gradual, over several weeks with increment in improvement continuing when patients were followed up for longer periods. Bereznai, ${ }^{30}$ however, reports more immediate motor improvement.

In our cases, the stimulator output was tailored for optimum benefit in each patient (Table 2). The previously reported ${ }^{25,28}$ current output has a mean of $4.0 \mathrm{~V}$, pulse width range 90-210, and mean frequency of $130 \mathrm{~Hz}$ which is similar to our findings. The optimum stimulation parameters are still not clear and many factors come into play including the latency of clinical response after changing output parameters, the exact location of the electrodes in the globus pallidus, presence of side effects, a possible dissociation between the response of pain and dystonia to various stimulation parameters and finally the important possibility of placebo effects. The exact mechanism of action of DBS remains unknown, and study of more cases will be required to determine the optimum stimulation parameters.

This report and previous literature suggest that GPi DBS is a promising new line of management in selected cases of refractory and disabling CD. The TWSTRS (total and sub scores) is a useful tool for the assessment of progress after surgery and comparing results between different groups. Patients should be informed that improvement is often delayed and gradual after surgery. Most improvement occurs during the first two to three months. Repeated fine tuning in programming of the pulse generator is necessary during follow-up maintenance of optimum benefit.

\section{REFERENCES:}

1. Dauer WT, Burke RE, Greene P, Fahn S. Current concepts on the clinical features, aetiology and management of idiopathic cervical dystonia. Brain 1998; 121(Pt 4): 547-560.

2. Fahn S, Marsden C, Calne DB. Clarification and investigation of dystonia. In: Fahn S, (Ed). Movemement Disorders. London: Butterworth Int Med Rev 1987; 323-361.

3. Claypool DW, Duane DD, Ilstrup DM, Melton LJ, 3rd. Epidemiology and outcome of cervical dystonia (spasmodic torticollis) in Rochester, Minnesota. Mov Disord 1995; 10(5): 608-614.

4. Jankovic J, Schwartz K. Response and immunoresistance to botulinum toxin injections. Neurology 1995; 45(9): 1743-1746.

5. Anderson T. Spasmodic torticollis. In: Moore P, (Ed). Handbook of Botulinum Toxin Treatment. Oxford: Blackwell Science, 1995; 103-130.

6. Villavicencio AT, Friedman AH. Surgery for Spasmodic Torticollis. In: Lozano AM, (Ed). Movement Disorder Surgery, vol 15. Basel: Karger, 2000; 296-330. 
7. Lang AE. Surgical treatment of dystonia. Adv Neurol 1998; 78: 185 198.

8. Hassler R, Hess WR. Experimentelle und anatomische befunde uber die drehbewegungen and ihrenervosen apparate. Arch Psychiatr Nervenkr 1954; 192: 488-526.

9. von Essen C, Augustinsson LE, Lindqvist G. VOI thalamotomy in spasmodic torticollis. Appl Neurophysiol 1980; 43(3-5): 159-163.

10. Laitinen LV, Vilkki J. Observations on physiological and psychological functions of the ventral oral internal nucleus of the human thalamus. Acta Neurol Scand 1977; 55(3): 198-212.

11. Cooper IS. Neurosurgical treatment of the dyskinesias. Clin Neurosurg 1977; 24: 367-390.

12. Andrew J, Fowler CJ, Harrison MJ. Stereotaxic thalamotomy in 55 cases of dystonia. Brain 1983; 106 ( Pt 4): 981-1000.

13. Eidelberg D, Moeller JR, Antonini A, et al. Functional brain networks in DYT1 dystonia. Ann Neurol 1998; 44(3): 303-312.

14. Vitek JL, Zhang J, Evatt M, et al. GPi pallidotomy for dystonia: clinical outcome and neuronal activity. Adv Neurol 1998; 78: 211-219.

15. Lenz FA, Suarez JI, Metman LV, et al. Pallidal activity during dystonia: somatosensory reorganisation and changes with severity. J Neurol Neurosurg Psychiatry 1998; 65(5): 767-770.

16. Lin JJ, Lin GY, Shih C, et al. Benefit of bilateral pallidotomy in the treatment of generalized dystonia. Case report. J Neurosurg 1999; 90(5): 974-976.

17. Iacono RP, Kuniyoshi SM, Lonser RR, et al. Simultaneous bilateral pallidoansotomy for idiopathic dystonia musculorum deformans. Pediatr Neurol 1996; 14(2): 145-148.

18. Lozano AM, Kumar R, Gross RE, et al. Globus pallidus internus pallidotomy for generalized dystonia. Mov Disord 1997; 12(6): 865-870.

19. Yoshor D, Hamilton WJ, Ondo W, Jankovic J, Grossman RG. Comparison of thalamotomy and pallidotomy for the treatment of dystonia. Neurosurgery 2001; 48(4): 818-824.

20. Eltahawy HA, Saint-Cyr J, Giladi N, Lang AE, Lozano AM. Primary dystonia is more responsive than seconday dystonia to pallidal interventions: outcome after pallidotomy or pallidal deep brain stimulation. Neurosurgery 2004; 54(3): 613-619.

21. Tarsy D. Comparison of clinical rating scales in treatment of cervical dystonia with botulinum toxin. Mov Disord 1997; 12(1): 100-102.

22. Lindeboom R, Brans JW, Aramideh M, Speelman HD, De Haan RJ. Treatment of cervical dystonia: a comparison of measures for outcome assessment. Mov Disord 1998; 13(4): 706-712.

23. Comella CL, Stebbins GT, Goetz CG, et al. Teaching tape for the motor section of the Toronto Western Spasmodic Torticollis Scale. Mov Disord 1997; 12(4): 570-575.

24. Lozano A, Hutchison W, Kiss Z, et al. Methods for microelectrodeguided posteroventral pallidotomy. J Neurosurg 1996; 84(2): 194-202.

25. Krauss JK, Pohle T, Weber S, Ozdoba C, Burgunder JM. Bilateral stimulation of globus pallidus internus for treatment of cervical dystonia. Lancet 1999; 354(9181): 837-838.

26. Kulisevsky J, Lleo A, Gironell A, et al. Bilateral pallidal stimulation for cervical dystonia: dissociated pain and motor improvement. Neurology 2000; 55(11): 1754-1755.

27. Islekel S, Zileli M, Zileli B. Unilateral pallidal stimulation in cervical dystonia. Stereotact Funct Neurosurg 1999; 72(2-4): 248-252.

28. Parkin S, Aziz T, Gregory R, Bain P. Bilateral internal globus pallidus stimulation for the treatment of spasmodic torticollis. Mov Disord 2001; 16(3): 489-493.

29. Andaluz N, Taha JM, Dalvi A. Bilateral pallidal deep brain stimulation for cervical and truncal dystonia. Neurology 2001; 57(3): 557-558.

30. Bereznai B, Steude U, Seelos K, Bozel K. Chronic high-frequency globus pallidus internus stimulation in different types of dystonia: a clinical, video, and MRI report of six patients presenting with segmental, cervical, and generalized dystonia. Mov Disord 2002; 17(No 1): 138-144.

31. Krauss JK, Loher TJ, Pohle T, et al. Pallidal deep brain stimulation in patients with cervical dystonia and severe cervical dyskinesias with cervical myelopathy. J Neurol Neurosurg Psychiatry 2002; 72(2): 249-256. 